\title{
Life test of a high temperature PEM fuel cell prepared by electrospray
}

Diego Úbedaa , Pablo Cañizares ${ }^{a}$, Paloma Ferreira-Aparicio ${ }^{b}$, Antonio M. Chaparrob, Justo Lobatoa, Manuel A. Rodrigoa,

${ }^{a}$ Department of Chemical Engineering. University of Castilla-La Mancha. Spain.

${ }^{b}$ Dep. of Energy. CIEMAT. Avda. Complutense 40. 28040 Madrid. Spain.

\begin{abstract}
A life test has been conducted to a PBI-based membrane-electrode assembly (MEA) in which the anode and cathode catalyst layers were prepared by electrospray and results were compared with a previous study in which the catalyst layer was prepared by airbrushing. During the study, the average and local current density were continually monitored and several diagnostic techniques were periodically applied, including polarization curves, cyclic voltammetries, electrochemical impedance spectroscopy and computational fluid dynamics modeling (CFD). Results show that significantly better fuel cell performance is achieved by the electrosprayed MEA, by about $40 \%$, as compared with the MEA prepared by traditional airbrushing with the same catalyst loading. According to the experimental measurements, the higher electrochemical active surface area and more favorable mass transport are the main responsible for the improved yield. Modeling estimations agree with experimental observations and corroborate better mass transport properties of the catalyst layer when using electrospray. This can be explained by a more appropriate morphology of the layer. No evidence of positive effects on the lifetime of the fuel cell was found out. At the end of the lifetest, the local concentrations of platinum (Pt) and phosphorus $(\mathrm{P})$ in the degraded MEA were analyzed and a correlation between Pt loading profile and local current distribution could be established.
\end{abstract}

Keywords: Electrospray, PBI, PEM fuel cell, life study, postmortem. 


\section{Introduction}

One of the main problems that limit the introduction of fuel cells in the market and their massive commercialization is their high price. Therefore, institutions such as the European Commission and the Department of Energy of the U.S.A include in their guidelines the reduction of production cost as one of the key points for fuel cells to be commercialized in the near future $[1,2]$. In the case of PEMFC there is an item of the investment cost of great relevance: the catalyst. Doing a rough estimation, platinum may represent around $40 \%$ of the total cost of a PEM fuel cell, in both low and high temperature technologies.

The reduction of Pt loading without severely affecting fuel cell performance is possible by several means, being one of them the improvement of electrode preparation and Pt deposition [3]. There exists a number of different methods to prepare electrodes (tape-casting, spraying, painting, sputtering, filtering, etc.) for a PEM fuel cell [4-9] and all of them aim at achieving a proper morphology and structure in order to attain better catalyst utilization. Amongst them, one of the most promising is the electrospray deposition of a catalyst ink onto the gas diffusion layer.

The electrospray deposition technique, which was applied to the preparation of electrodes for low temperature PEM fuel cells by Baturina and Wnek [10] and Benítez et al. $[11,12]$, consists of the generation of an aerosol phase from a suspension of particles, thanks to the action of a strong electric field. When it is employed to make PEMFC electrodes, the electric potential is applied between an ejector needle and the substrate where the catalyst layer needs to be deposited. A suspension containing the different components of the catalyst layer (ink) is transferred into an aerosol, which is formed by highly disperse charged particles that deposit on the substrate under the electrostatic interaction. Under appropriate conditions, a film with high catalytic performance and porous dendritic morphology can be obtained. Such film is characterised by a highly porous structure in the 
meso- and macroporosity range, with pore volumes per gram of carbon of up to 12 $\mathrm{cm}^{3} / \mathrm{gc}_{\mathrm{c}}$ against $1.8-2.5 \mathrm{~cm}^{3} / \mathrm{gc}_{\mathrm{c}}$ for standard airbrushed layers, as measured with mercury porosimetry [13]. Model estimations of the catalyst layer porosity in this work corroborate the important porosity increase with electrosprayed films. A recent localized reference electrode study has shown that the high porosity of the catalyst layer favors lateral homogeneity of cell response as a consequence of improved mass transport within the cell [14]. Ultra-low platinum loadings have been used with promising results in Nafion-based fuel cells [15-17], obtaining a comparable performance to electrodes prepared by sputtering.

Most studies with electrosprayed catalyst layer have been mostly dedicated to their application in low temperature PEMFC. The first study, to our knowledge, on the use of electrospray-prepared electrodes in PBI-based PEM fuel cells has been communicated in Ref. [18] showing improved performance with respect to conventional layers prepared with airbrushing. The porous morphology of the electrosprayed layers improves reactants accessibility and transport within the catalyst layer also within a PBI based cell. However, no information was reported about the stability of this cell type when using electrosprayed catalyst layer. A change in stability is to be expected with catalyst layer morphology, since degradation processes like carbon corrosion and platinum dissolution, also depend on mass transport properties under certain conditions. For instances, in a cell operated under high current density, corrosion reactions may exacerbate by localized starvation phenomena and lateral inhomogeneities that appear as a consequence of slow mass transport. Such phenomena are especially acute in low temperature PEMFC due to the presence of liquid water that must be transported through the porous medium at a high rate [19-21]. In PBI cells working at higher temperatures, water transport in the vapor phase may be faster, although corrosion reactions are accelerated by the higher working temperature. It is, therefore, of high interest to analyse if there is an effect of the electrosprayed layer on the durability of this type of cell. 
In this paper, we aim at studying the break-in and degradation (typical life test) of a PBI PEM fuel cell whose electrodes have been prepared by the electrospray technique, identifying the reasons that cause it by means of experimental characterization (including current density distribution, electrochemical characterization with different techniques and physico-chemical characterization of the MEA after the life test). Experimental results are complemented with modelling based on computational fluid dynamics, as developed in previous works [22-24]. It is also of interest to compare the results obtained in this study with those of the life test study performed to the MEA presented in Ref. [25], prepared by manual airbrush.

\section{Experimental and modeling}

\section{MEA preparation}

To prepare the membrane-electrode assembly (MEA), two $49 \mathrm{~cm}^{2}$ square electrodes with $0.25 \mathrm{mg} \mathrm{cm}^{-2} \mathrm{Pt}$ loading, the same as that used in Ref. [25], were fabricated. In the first place, a microporous layer constituted by carbon black (Vulcan XC-72) and polytetrafluoroethylene was manually sprayed onto a piece of carbon fiber paper (TORAY TGPH-90) until the desired carbon loading was achieved. Next, the catalyst layer was deposited using the electrospray technique [13]. In order to prepare the catalytic ink, Pt/C (E-TEK 40 wt. \% Pt on carbon Vulcan XC72) and polybenzimidazole (PBI) were dispersed into a dimethylacetamide solution. Then, the electrodes were assembled by hot-pressing them with a PBI membrane in between. This membrane had previously been casted from a PBI solution and immersed into a 75 wt. $\% \mathrm{H}_{3} \mathrm{PO}_{4}$ bath until a doping level of around eight molecules of acid per polymer repeating unit was reached. 
The so-prepared MEA was inserted between two graphite end plates where 4-

step serpentine flow channels are mechanized. A sensor plate for current distribution measurement (,++ Germany) was placed behind the end plate of the cathode side. Finally two additional thick plates that provide with mechanical support and allow for heating the device by means of integrated electric heaters were also disposed. A detailed description of the arrangement is available in Ref. [26].

\section{Lifetime study}

The lifetime study was performed respecting the procedure applied in Ref [25]. Essentially, this consisted of the operation of the fuel cell at $150{ }^{\circ} \mathrm{C}$ and at a constant potential of $0.60 \mathrm{~V}$ while the average and local current density values were recorded. Additional electrochemical tests were carried out periodically in order to assess at different times the global performance of the fuel cell and its components. Thus, the continuous operation was regularly interrupted to perform polarization curves, cyclic voltammetries, hydrogen crossover measurements and electrochemical impedance spectroscopy (EIS). A potentiostat/galvanostat (Ecochemie, The Netherlands) coupled with a Frequency Response Analyzer (FRA) was used for this purpose.

Throughout the lifetime study, $100 \mathrm{~mL} \mathrm{~min}^{-1}$ (STP) dry hydrogen and $100 \mathrm{~mL}$ $\min ^{-1}(\mathrm{STP})$ dry pure oxygen were fed. Polarization curves were performed at a scan rate of $1 \mathrm{mV} \mathrm{s}^{-1}$ at the same operating temperature as the lifetest. Inlet flow rates were $675 \mathrm{~mL} \mathrm{~min}^{-1}(\mathrm{STP})$ dry air and $211 \mathrm{~mL} \mathrm{~min}^{-1}$ (STP) dry hydrogen. Current density distribution was simultaneously measured, recording a map every $0.5 \mathrm{~s}$, which allowed the obtaining of local polarization curves as well as the evolution of local current density. Cyclic voltammetries were carried out at a scan rate of 100 $\mathrm{mV} \mathrm{s}^{-1}$ and again at operating temperature. Measuring the areas at high temperature gives rise to lower absolute values due to thermodynamics and kinetics changes [27] but it allows following area changes without altering the 
degradation process. Humidified $\mathrm{N}_{2}$ was fed to the cathode side, while dry hydrogen was introduced in the anode side. The integration of hydrogen desorption peak was the way used to evaluate the cathode electrochemical active surface area. The same cell configuration was used to measure hydrogen crossover current at $0.5 \mathrm{~V}$. Impedance spectra experiments at $i=0.02 \mathrm{~A} \mathrm{~cm}^{-2}$ and at $E_{\text {cell }}=0.70 \mathrm{~V}$ were performed to measure membrane resistance and charge transfer resistance. Dry pure oxygen and dry hydrogen were used.

\section{Post-mortem analysis}

A physico-chemical study of the degraded MEA was carried out. This postmortem analysis was performed by taking the MEA out from the fuel cell once the life study was completed and dividing it into 16 portions. Then, the platinum (Pt) and phosphorus (P) content of each piece were measured. To this end, they were separately treated in aqua regia $\left(\mathrm{HNO}_{3} / \mathrm{HCl} 1: 3\right)$ and heated up in a microwave oven (Ethos Plus, Milestone, U.S.A.) to boost the acid attack. The thermal treatment consisted of a temperature ramp from $25^{\circ} \mathrm{C}$ to $190^{\circ} \mathrm{C}$, finishing with a 10 min period at this temperature. The samples were cooled at room temperature for $24 \mathrm{~h}$ to finally measure $\mathrm{P}$ and Pt concentration by the use of ICP-AES (Liberty Sequential, VARIAN, U.S.A.). The results obtained were related to the Pt and P loading of the MEA portion.

\section{Modelling}

A simulation tool was applied to assess the conditions of the different components of the fuel cell during the lifetime study. This tool is based on the implementation of a high temperature full-cell model in COMSOL Multiphysics v 3.5. After a thorough sensitivity analysis applied to the relevant parameters, a methodology to evaluate the most representative properties of the fuel cell at local level could be proposed. References [22-24] can be consulted if more information is desired. 


\section{Results and discussion}

Figure 1 shows the average current density measured at $E_{\text {cell }}=0.60 \mathrm{~V}$ throughout the life test. For comparison purposes, the study commented in Ref. [25] (MEA made by airbrushing) has been overlaid.

\section{Figure 1 over here}

The average current density measured to the MEA prepared by electrospray was significantly higher. The performance improvement with respect to the airbrush assembly is around $40 \%$ in terms of output power density. In the new assembly, the conditioning-degradation trend can be clearly observed also. Like for the airbrush assembly, the maximum average current density is reached after $37 \mathrm{~h}$. Apparently, the best performance is kept for some hours, and then a decay is observed.

The curves show periodic transient steps which correspond to start-stop events to proceed with characterization. Each peak matches with the restart of normal operation after the interruption to perform additional measurements. According to Cleghorn et al. [28], this performance recovery would correspond to reversible losses whose sources are removed during the interruption periods. Formation of Pt oxides and adsorption of poisons in the catalyst (which are removed while occurred to a much lower extent.

At $197 \mathrm{~h}$, the average current density generated decayed $10 \%$ with respect to the initial value, which indicates improved durability for the electrospray-prepared MEA. In fact, the initial improvement during the break-in is larger for this cell, which makes that $90 \%$ of the initial current density is reached at later time. The average current density decay rate from the end of the activation stage until the 
end of the experiment was $0.246 \mathrm{~mA} \mathrm{~cm}^{-2} \mathrm{~h}^{-1}$, whereas for the assembly prepared by airbrush was $0.254 \mathrm{~mA} \mathrm{~cm}{ }^{-2} \mathrm{~h}^{-1}$, which apparently indicates that the deposition method does not significantly affect the performance loss rate.

Localized current measurements give more insight into the response of the cells. These measurements were also obtained during the entire life test, so the evolution of local current density is available. The sensor plate for current distribution measurement counts with 100 segments $\left(0.25 \mathrm{~cm}^{2}\right.$ each $)$, but, for the sake of clarification, the cell has been (fictitiously) divided into 16 regions only, representing each one the average current density of the group of segments comprised in the region in question. Figure 3 shows the local evolution of current density in the different regions. Again, the assembly prepared by airbrushing has been included in the figure for comparison.

\section{Figure 2 over here}

\section{Figure 3 over here}

All the regions show the same general trend of activation-degradation, as observed in Fig.1. Curves appear, however, shifted vertically indicating that the current density generated in each region is different, and there are also some differences in their activation and degradation rates. Central segments $(6,7,10,11)$ show higher response over time. Figure 4 shows relative standard deviation of the average current density during the break-in. The results obtained in Ref. [25] have also been included with grey markers and dashed grey line. (This colour code will be repeated in the rest of figures where a comparison is made between the airbrush and the electrospray-prepared MEAs). Relative Standard Deviation (RSD) is defined in Equation (1).

$$
217 \quad R S D=\sqrt{\frac{\sum\left(i_{s}-i\right)^{2}}{n}} / i
$$



standard deviation of the average current density remains constant in this period, demonstrating the same behaviour as in the previous assembly studied. Thus, it could be concluded that the RSD of the average current density does not change during the activation stage.

Figure 5 shows images of the current density distribution, expressed as relative deviation from the average current density, during the first $37 \mathrm{~h}$ of experiment for the electrospray cell. This representation type allows to follow lateral inhomogeinity in current response.

\section{Figure 4 over here}

\section{Figure 5 over here}

The central zone of the electrode is the most active, namely Regions 7 and 11 , whereas the corners show poorer performance. Although some minor changes can be observed, the map essentially keeps its profile during the whole period, repeating this assembly the behaviour observed for the airbrush MEA.

Figure 6 shows the RSD of the average current density during the degradation

\section{Figure 6 over here}

Figure 7 shows the current distribution maps during the degradation period. The relative differences between regions keep almost invariable until $117 \mathrm{~h}$ of experiment, moment when red colours move towards the right side of the electrode, indicating lower degradation rates of Regions 4, 8 and 12 . On the other 
hand, the appearance of lighter colours in Regions 6 and 8 denotes that they loss their activity more quickly than the rest. The time when shifts in Figure 7 start to be noticed coincides with the beginning of RSD increase observed in Figure 6, in the same way that occurred with the airbrush assembly. This leads to associate a change in the Relative Standard Deviation of the average current density with a shift in the current density distribution map and with a decrease in the fuel cell performance. For the reader's convenience, the evolution of current density distribution during the lifetime study performed to the airbrush assembly is presented in Figure 8.

\section{Figure 7 over here}

\section{Figure 8 over here}

As explained in Section 2, the normal operation was periodically interrupted in order to acquire more information on the performance of the fuel cell. Polarization curves allowed for the evaluation of the global and local performance under different loads, while cyclic voltammetries enabled to follow the evolution of electrochemically active surface area during the lifetime of the cell. Finally, EIS analysis was employed to measure the evolution of charge transfer and ohmic resistance.

Figure 9 shows the polarization curves obtained at different times of the life study. The evolution of the maximum power yielded by the fuel cell essentially agrees with the degradation trend observed in Figure 1. The polarization curves suggest that the degradation process of the two assemblies is caused by a combination of loss of catalytic activity, increase of ohmic resistance and worsening of mass transport properties. However, the degradation appears to be more intensive under higher loads for the airbursh assembly, which could be due to a quicker deterioration of mass transport properties. 
Figure 10 shows the most relevant results of the voltamperometric and EIS tests performed in order to study the catalyst conditions during the life study. Thus, the electrochemically active surface area (ESA) determined by cyclic voltammetry and the charge transfer resistance at $0.70 \mathrm{~V}$ determined by EIS analysis are plotted vs. operation time.

Figure 10 over here

The charge transfer resistance is lower in the electrodes prepared by electrospray and the values of ESA are significantly higher. This verifies that the better general performance observed in Figure 1 is in part due to better catalyst features when the catalyst layer is built-up by electrospray.

Figure 11 shows the evolution of electrolyte resistance at $i=0.02 \mathrm{~A} \mathrm{~cm}^{-2}$ (measured by EIS) as well as the crossover current density during the life test.

\section{Figure 11 over here}

It can be checked that the initial and final electrolyte resistance are comparable in both cases. However, the decrease observed in the electrospray assembly during the activation stage is much less important than in the airbrushed one. It is not expected that the deposition technique has such a strong influence on the conductivity of the system, hence the differences measured and estimated in the absolute values and their evolution must lie in some non-controlled variable due to the manual production of membranes. The crossover current observed in Figure $11(b)$ is very similar in both cases and stable during the whole operation time, which helps ascertain that membrane catastrophic failure did not occur.

With the experimental local polarization curves acquired during the life test and the assistance of CFD simulation, it was possible to assess the value of the characteristic parameters related to the fuel cell performance in the 16 regions considered and at different times of the experiment. The process involved the 
tuning of these parameters in order to fit the local polarization curves predicted by a validated model to those experimentally measured. The model predictions show trends for the cathode exchange current density and the electrolyte conductivity that agree well with their respective related parameters experimentally measured and presented in Figures 10 and 11. The estimations are particularly of interest in the case of the porosity of the electrode, parameter linked to the morphology of the catalyst layer that could not be experimentally measured during the test. According to the model, porosity is higher for the electrospray assembly (ca. $0.3 \mathrm{vs} 0.23$ at $\mathrm{t}=$ $0 \mathrm{~h}$ ). Furthermore, soon after the test starts, the porosity of the airbrush assembly porosity of the electrosprayed one (ca. 0.25 vs 0.1 at $t=227 \mathrm{~h}$ ). These results indicate that the electrospray assembly has a catalyst layer with more appropriate morphology for mass transport that is also more stable, which explains the observations made in Figure 9 at higher current loads. The complete model results can be consulted in Appendix A.

After the end of life of the assembly, the steps detailed in Section 2 were followed in order to obtain platinum and phosphorus distributions. These, together with the current density distribution map at the final time (Figure $7, t=227 \mathrm{~h}$ ) in a resolution of $4 \times 4$ have been represented in Figure 12.

\section{Figure 12 over here}

The platinum loading distribution shows a particular pattern, with higher concentration in the central zone getting lower towards the corners. This characteristic profile is a consequence of the electrospray process that has favoured deposition on the centre of the substrate than on the corners, following changes in the electric field intensity and creating a distribution as that shown in Figure 11(b). Although the Pt loading measured corresponds to the total amount (anode + cathode), it is very likely that the two electrodes had a very similar distribution 
given that Pt was deposited by an automatized procedure. Then, the combination of both should result in a pattern of the same shape. Thus, the catalyst relative loading distribution shown in Figure 12(b) can be considered a good approximation of the catalyst distribution of both cathode and anode separately.

The current density map (Figure 12(a)) has significant similarities with Pt distribution, with the difference that the center of activity is shifted towards the upper right-hand corner.

Figure 13 shows the parameter $i_{c}^{e x}$ calculated by the mathematical model plotted at four times of the life study. It is remarkable that the cathode exchange current density profiles at $\mathrm{t}=0 \mathrm{~h}$ and $\mathrm{t}=37 \mathrm{~h}$ are almost identical to the Pt loading distribution observed in Figure 12(b). This similarity is not so evident at $t=121 \mathrm{~h}$ and $t=227 \mathrm{~h}$, which indicates that the catalyst activity at these times is not only determined by Pt concentration. Thus, the possibility of a strong link between Pt loading distribution in the cathode and current density distribution is evident, especially at the beginning of the lifetime of the MEA. The post-mortem analysis carried out to the airbrushed MEA did not reveal this connection because it was not possible to guess the Pt loading profile in the cathode from the measured total Pt distribution.

\section{Figure 13 over here}

The PBI membrane thickness before assembly is shown in Figure 14. Thinner regions are not the most active, so apparently membrane unevenness is not a key issue in performance heterogeneity.

\section{Figure 14 over here}

The conductivity profile evaluated with the simulation tool, shown in Figure 15, does not undergo important relative changes during the life time of the fuel cell. In this case, the less conductive regions apparently coincide with the thicker zones of 
the membrane (Figure 14), but no resemblances with the $\mathrm{P}$ distribution can be observed.

\section{Figure 15 over here}

\section{Conclusions}

The application of the electrospray technique to build up the catalyst layers of a PBI-based high temperature PEMFC results in a remarkable performance improvement if compared with a MEA prepared by traditional airbrushing. According to experimental and modelling diagnostic tools applied, the improvement was due to better catalyst utilization and enhanced mass transport properties of the catalyst layer. In terms of durability, no relevant advances were achieved. The performance decay was found to be mainly caused by progressive loss of electrochemical active surface area, which suggests that catalyst agglomeration took place during the lifetime of the fuel cell. The catalyst distribution in the electrodes was not uniform and showed higher concentration in the center than in the corners. A very similar contour of local current density was measured during the life test, which revealed the correlation between local catalyst loading and local performance. No such a correlation could be inferred for phosphorus distribution or membrane thickness and the measured current density. Thus, further improvements in the catalyst deposition technique that lead to uniform Pt distribution could result in notable enhancement of fuel cell performance.

\section{Acknowledgements}

The authors further thank the European Commission as part of this work was supported by the Seventh Framework Programme through the project CISTEM (FCH-JU Grant Agreement Number 325262), and the project ELECTROFILM, MAT2011-27151 from Ministerio de Economía y Competitividad of Spain. 
380 [1] U.S.D.o.E. Office of Energy Efficiency \& Renewable Energy,

381 http://energy.gov/eere/fuelcells/key-activities, 23/08/2015

382 [2] E. Commission,

383 http://ec.europa.eu/research/energy/print.cfm?file=/comm/research/energy/nn/nn rt/nn rt fc/article 1139 en.htm, 23/08/2015

[3] A.M. Chaparro, R. Benítez, L. Gubler, G.G. Scherer, L. Daza, Study of membrane electrode assemblies for PEMFC, with cathodes prepared by the electrospray method, Journal of Power Sources, 169 (2007) 77-84.

[4] S. Litster, G. McLean, PEM fuel cell electrodes, Journal of Power Sources, 130 (2004) 61-76.

390 [5] P.K. Sheng, PEM Fuel Cell Catalyst Layers and MEAs, in: J. Zhang (Ed.) PEM 391 Fuel Cell Electrocatalysts and Catalyst Layers, Springer2008, pp. 355-374.

392 [6] R. Maric, Spray-based and CVD Processes for Synthesis of Fuel Cell Catalysts and Thin Catalyst Layers, in: J. Zhang (Ed.) PEM Fuel Cell Electrocatalysts and Catalyst Layers, Springer2008, pp. 917-958. [7] W. Xing, Catalyst Layer Composition Optimization, in: J. Zhang (Ed.) PEM Fuel Cell Electrocatalysts and Catalyst Layers, Springer2008, pp. 1003-1033. [8] T.-H. Huang, H.-L. Shen, T.-C. Jao, F.-B. Weng, A. Su, Ultra-low Pt loading for proton exchange membrane fuel cells by catalyst coating technique with ultrasonic spray coating machine, International Journal of Hydrogen Energy, 37 (2012) 13872-13879.

401 [9] H. Su, T.-C. Jao, O. Barron, B.G. Pollet, S. Pasupathi, Low platinum loading for 402 high temperature proton exchange membrane fuel cell developed by ultrasonic spray coating technique, Journal of Power Sources, 267 (2014) 155-159.

404 [10] O.A. Baturina, G.E. Wnek, Characterization of Proton Exchange Membrane Fuel

405 Cells with Catalyst Layers Obtained by Electrospraying, Electrochemical and Solid406 State Letters, 8 (2005) A267-A269.

407 [11] R. Benítez, J. Soler, L. Daza, Novel method for preparation of PEMFC 408 electrodes by the electrospray technique, Journal of Power Sources, 151 (2005) $409 \quad 108-113$.

410 [12] R. Benítez, A.M. Chaparro, L. Daza, Electrochemical characterisation of Pt/C 411 suspensions for the reduction of oxygen, Journal of Power Sources, 151 (2005) 2412 10. 

Álvarez, L. Daza, Properties of Catalyst Layers for PEMFC Electrodes Prepared by Electrospray Deposition, Journal of the Electrochemical Society, 157 (2010) B993B999.

417 [14] A.M. Chaparro, P. Ferreira-Aparicio, M.A. Folgado, E. Brightman, G. Hinds,

418 Study of superhydrophobic electrosprayed catalyst layers using a localized reference electrode technique, Journal of Power Sources, 325 (2016) 609-619. [15] S. Martin, P.L. Garcia-Ybarra, J.L. Castillo, Electrospray deposition of catalyst layers with ultra-low Pt loadings for PEM fuel cells cathodes, Journal of Power Sources, 195 (2010) 2443-2449. [16] S. Martin, P.L. Garcia-Ybarra, J.L. Castillo, High platinum utilization in ultralow Pt loaded PEM fuel cell cathodes prepared by electrospraying, International Journal of Hydrogen Energy, 35 (2010) 10446-10451. [17] S. Martin, B. Martinez-Vazquez, P.L. Garcia-Ybarra, J.L. Castillo, Peak utilization of catalyst with ultra-low Pt loaded PEM fuel cell electrodes prepared by the electrospray method, Journal of Power Sources, 229 (2013) 179-184. [18] J. Lobato, M.A. Rodrigo, P. Canizares, J.J. Linares, A.M. Chaparro, M.A. Folgado, L. Daza, Electrodes prepared by electrospray for high temperature PBIbased PEMFC, in: ASME (Ed.) Second European Fuel Cell Technology and Applications ConferenceRome, 2007, pp. 23-24.

433 [19] T.W. Patterson, R.M. Darling, Damage to the Cathode Catalyst of a PEM Fuel 434 Cell Caused by Localized Fuel Starvation, Electrochemical and Solid-State Letters, 9 435 (2006) A183-A185.

436 [20] C. Hartnig, I. Manke, R. Kuhn, S. Kleinau, J. Goebbels, J. Banhart, High437 resolution in-plane investigation of the water evolution and transport in PEM fuel 438 cells, Journal of Power Sources, 188 (2009) 468-474.

439 [21] S. Ohyagi, T. Matsuda, Y. Iseki, T. Sasaki, C. Kaito, Effects of operating 440 conditions on durability of polymer electrolyte membrane fuel cell Pt cathode 441 catalyst layer, Journal of Power Sources, 196 (2011) 3743-3749.

442 [22] J. Lobato, P. Cañizares, M.A. Rodrigo, F.J. Pinar, E. Mena, D. Úbeda, Three443 dimensional model of a $50 \mathrm{~cm}^{2}$ high temperature PEM fuel cell. Study of the flow 444 channel geometry influence, International Journal of Hydrogen Energy, 35 (2010) 445 5510-5520.

446 [23] D. Úbeda, F.J. Pinar, P. Cañizares, M.A. Rodrigo, J. Lobato, An easy parameter 447 estimation procedure for modeling a HT-PEMFC, International Journal of Hydrogen 448 Energy, 37 (2012) 11308-11320. 
449 [24] D. Úbeda, P. Cañizares, M.A. Rodrigo, F.J. Pinar, J. Lobato, Durability study of 450 HTPEMFC through current distribution measurements and the application of a 451 model, International Journal of Hydrogen Energy, 39 (2014) 21678-21687.

452 [25] D. Úbeda, F. Pinar, D. Orozco, P. Cañizares, M. Rodrigo, J. Lobato, Life study 453 of a PBI-PEM fuel cell by current distribution measurement, Journal of Applied 454 Electrochemistry, 42 (2012) 711-718.

455 [26] J. Lobato, P. Cañizares, M.A. Rodrigo, F.J. Pinar, D. Úbeda, Study of flow 456 channel geometry using current distribution measurement in a high temperature 457 polymer electrolyte membrane fuel cell, Journal of Power Sources, 196 (2011) 458 4209-4217.

459 [27] A.M. Chaparro, A.J. Martín, M.A. Folgado, B. Gallardo, L. Daza, Comparative 460 analysis of the electroactive area of Pt/C PEMFC electrodes in liquid and solid 461 polymer contact by underpotential hydrogen adsorption/desorption, International 462 Journal of Hydrogen Energy, 34 (2009) 4838-4846.

463 [28] S.J.C. Cleghorn, D.K. Mayfield, D.A. Moore, J.C. Moore, G. Rusch, T.W. 464 Sherman, N.T. Sisofo, U. Beuscher, A polymer electrolyte fuel cell life test: 3 years 465 of continuous operation, Journal of Power Sources, 158 (2006) 446-454.

$471 i \quad$ current density $\left(\mathrm{A} \mathrm{m}^{-2}\right)$

$472 \quad n \quad$ number of segments

$473 \quad R \quad$ resistance $\left({\left.\mathrm{Ohm} \mathrm{cm}^{-2}\right)}^{2}\right.$ 
conductivity ( $\left.\mathrm{S} \mathrm{m}^{-1}\right)$

479

480

Subscripts and superscripts

481

482 C cathode

483 cell cell

$484 \quad c t \quad$ charge transfer

485 ex exchange

486 I electrolyte phase

487 mem membrane

$488 \quad S \quad$ segment 